\title{
LOS EJEMPLOS DE LAS TÉCNICAS DECIMONÓNICAS: EL FERROCARRIL*
}

\author{
Francesc Rodríguez Ortiz
}

Universitat Autònoma de Barcelona

\section{RESUMEN}

Los lenguajes de especialidad han sido tratados, en los últimos años, desde un punto de vista filológico. No obstante, su análisis se ha planteado principalmente desde disciplinas terminológicas, con el objetivo de delimitar y unificar en el presente el corpus léxico de una rama específica del saber. En algunas ocasiones, su estudio se ha centrado en su posible caracterización teórica, en relación con el lenguaje común o con otros lenguajes. Ambas perspectivas, entendidas como intentos por delimitar cuantitativa y cualitativamente determinadas parcelas del léxico, no han incidido en demasía en dos aspectos fundamentales. En primer lugar, en el trazado de un itinerario histórico-lingüístico de la adopción y desarrollo de un grupo de términos comunes a una ciencia, a una técnica o a una profesión, con los textos en la mano; en segundo lugar, en la necesidad de establecer las relaciones que existen entre lengua, cultura y sociedad en los momentos de aparición y evolución de un lenguaje de especialidad. Por tanto, esta vertiente une el lenguaje con la historia de las ciencias y de las técnicas, sin restringir en ningún momento la explicación de los hechos lingüísticos al ámbito filológico.

Este es el objetivo de este artículo: analizar y exponer exhaustivamente el proceso de introducción y desarrollo del léxico del ferrocarril en el español, teniendo en cuenta los documentos originales, la historia de los términos y el transcurrir paralelo de los mismos respecto a la evolución técnico-científica de nuestro país en materia ferroviaria.

PALABRAS CLAVE: léxico, terminología, ferrocarril, vocabulario.

\section{SUMMARY}

The languages of specific themes have been treated, in the last years, from a philological point of view. Nevertheless, their analysis has been expounded mainly from terminological disciplines, with the objective of defining and unifies the corpus lexical of a specific branch of the knowledge presently. In some other occasions, their study has been centered in their possible theoretical characterization, in connection with the common language or with other languages. Both perspectives there aren't fall into two fundamental looks. In first place, in the tracing of a historical-linguistic itinerary of the adoption of a group of common terms to a science, to a technique or to a profession, with the texts in the hand; in second place, in the necessity of establishing the relationships that exist between language, culture and society in the moments of apparition and evolution of a language of specialty.

* Este estudio se enmarca en el proyecto de investigación Catálogo de neologismo del léxico científico y técnico del S. XIX, financiado parcialmente por el MCYT (BFF2001-2478). 
This is the objective of this dissertation: analyzing the process of introduction and development from the lexicon of the railroad in the Spanish language, keeping in mind the original documents, the history of the terms and their lapse parallel to the technician-scientific Spanish evolution in rail matter.

KEY WORDS: lexicon, terminology, railroad, vocabulary.

El culto griego a Asclepio - héroe y dios de la Medicina- se estableció principalmente en Epidauro (Peloponeso), donde se desarrolló una verdadera escuela médica. Inicialmente, sus prácticas eran sobre todo mágicas, pero prepararon el advenimiento de una medicina más científica.

Esta referencia clásica inicial se halla completamente justificada en nuestro caso. Es bien sabido que la reconstrucción de la historia de la ciencia y de la técnica no puede ignorar el análisis de los lenguajes de especialidad, originados con la implantación de distintos avances a lo largo de los tiempos. A su vez, esta labor no puede estar basada en simples artes adivinatorias. Nuestra propia magia debe manejar, en todo caso, los documentos y referencias históricas que en cada momento generaron las nuevas disciplinas. Y ello, siempre a través de un método planteado con rigor científico en cuanto a la selección $\mathrm{y}$ análisis del material terminológico.

En el caso concreto del ferrocarril a lo largo del siglo XIX y, por extensión, en los estudios parciales que puedan realizarse en otros ámbitos científico-técnicos resulta por tanto ineludible una especial atención a las siguientes cuestiones $^{1}$.

\section{Lengua, Cultura y Sociedad}

Hasta el momento, los intentos por delimitar cuantitativa y cualitativamente determinadas parcelas del léxico no han incidido en demasía en dos aspectos que debemos considerar fundamentales. En primer lugar, en el trazado de un itinerario histórico-lingüístico de la introducción y desarrollo de un grupo de términos comunes a una ciencia, técnica o profesión, con los textos en la mano; en segundo lugar, en la necesidad de establecer las relaciones que existen entre lengua, cultura y sociedad en los momentos de aparición y evolución de un lenguaje de especialidad. Por tanto, es necesario unir lenguaje y realidad, confrontar los hechos de lengua con los acontecimientos históricos de las ciencias y de las técnicas, sin restringir en ningún momento la explicación de estos hechos lingüísticos al ámbito filológico.

1 Más información en RodRíguez OrTIZ, F. (1997). 


\section{FUENTES DE DOCUMENTACIÓN}

a) Tratados y manuales técnicos

En un primer momento, correspondieron a traducciones españolas (1831$1833)^{2}$ de manuales ferroviarios franceses $(1826-1828)^{3}$ que, a su vez, siguieron fundamentalmente los textos originales del ingeniero inglés Thomas Tredgold. La motivación de los técnicos españoles para el manejo de las obras francesas fue su incorporación del sistema métrico decimal, cuya adaptación se estaba gestando en esos momentos. El proceso, iniciado en la última década del siglo XVIII, culminó en Francia el 4 de julio de 1837, y en España, con la Ley de Pesos y Medidas, en 1849, aunque el período de implantación definitiva en régimen de préstamo lingüístico del francés se prolongó hasta 1875 con la adhesión al Convenio de París (Gutiérrez Cuadrado; Peset, 1997).

La relación entre fuentes francesas y españolas influyó también en la incorporación de terminología relacionada, por ejemplo, con los vehículos ferroviarios o las infraestructuras de la nueva vía de comunicación (Rodríguez Ortiz, 1998a). Esta influencia galicista convivió, por otra parte, con el empuje de las voces inglesas o sus soluciones equivalentes en lengua española. De este modo, tras los primeros intentos ferroviarios peninsulares, es posible fijar en 1829 la documentación de la expresión camino de hierro ${ }^{4}$ - del equivalente francés chemin en fer, que formó parte de un total de dieciséis denominaciones de estructura similar- o, poco después, del término ferrocarril (Rodríguez Ortiz, 2001) en textos publicados en Cuba, donde, desde 1834, trabajó un grupo de contratistas norteamericanos con mano de obra de origen canario. Así, el proceso de reconstrucción lingüística adquiere su razón de ser una vez conocido el contexto histórico-social de la implantación del ferrocarril en los territorios de habla hispana.

Será más adelante, a partir de 1844, cuando aparecerán los primeros textos españoles especializados en el ferrocarril. Durante dos décadas, coincidiendo

2 GonzÁlez Azaola, G. (1831); Escosura, G. de la (1831); BARrA, F.J. (1833). Esta última obra tiene su origen en una memoria de F. de Gerstner, impresa en Praga en 1813, y traducida del alemán al francés por el ingeniero Pierre Simon Girard en 1827, cuya versión manejó posteriormente Fco. Javier Barra.

3 Duverne, T. (1826); Mellet, F.N. (1828). A estos textos se une la obra de P.S. Girard citada en la nota anterior.

4 En Calero y Portocarrero, M. (1929-1931), Semanario de Agricultura y Artes, Londres. Para descubrir la importancia de esta publicación periódica y de su autor en la historia ferroviaria española, vid. RODRÍGUEZ ORTIZ, F. (1996). 
con las publicaciones surgidas hasta 1864, a raíz de la Exposición Universal de Londres en 1862, la producción propia de manuales técnicos fue en aumento hasta llegar a la larga lista de documentos editados durante el último cuarto de siglo con una redacción original en lengua española.

\section{b) Documentación técnico-administrativa}

Aunque entre 1829 y 1834 se produjeron diversas actuaciones administrativas para desarrollar unos primeros trazados ferroviarios (Jerez-San Lúcar, Bilbao-Burgos o Reus-Tarragona), ninguno de los proyectos presentados llegó a cuajar. Además, un largo paréntesis se abrió en España hasta 1843, con el estallido de las guerras carlistas y la regencia del general Espartero. Únicamente con la aparición del primer informe técnico sobre ferrocarriles en lengua española, el Informe Subercase, que vio la luz en Madrid el dos de noviembre de 1844, se abrió de nuevo el camino a la publicación de prospectos, memorias e instrucciones en el ámbito administrativo (Barcelona-Mataró, Madrid-Aranjuez, Barcelona-Camprodón, Madrid-Avilés, Madrid-Cádiz o Madrid-Cartagena). Sólo algunos de estos proyectos ferroviarios tuvieron un final feliz, pero las bases quedaron sentadas para que en torno a la primera Ley General de Ferrocarriles de nuestro país, promulgada en 1855, el despegue de la explotación del ferrocarril español fuese definitivo.

\section{c) Obras legislativas}

Hasta diciembre de 1844 no fue publicado en España un Pliego General de condiciones para la solicitud y obtención de concesiones ferroviarias, surgido tras el Informe Subercase. Diversos cambios ministeriales y ciertos momentos de transición política provocaron, en un primer momento, la desviación del programa nacional de ferrocarriles (secundado por los progresistas) $\mathrm{y}$, a continuación, la solapada protección gubernamental (con el apoyo de los moderados) a iniciativas aisladas, ajenas al marco de una ley general que fijara las líneas prioritarias. La revolución de julio de 1854 y una serie de fuertes discusiones parlamentarias sobre las que habían de ser las líneas ferroviarias de primer orden precedieron a la aprobación, en 1855, de la primera Ley General. Con ello, la confianza de los inversores y el reclamo que suponía esta nueva situación para los capitales europeos permitieron en poco más de veinte años —en especial durante el quinquenio de 1860 a 1865 - un acercamiento 
de nuestro país a las cotas alcanzadas por el resto de naciones. La expansión exigió la elaboración de un nuevo plan general sobre la totalidad de la red, integrado en la Ley de Ferrocarriles de 1877. Entre ambas leyes, la edición de numerosos estatutos y reglamentos de sociedades ferroviarias constituyen una fuente documental relevante.

\section{d) Prensa especializada}

El Semanario de Agricultura y Artes, editado en Londres por el español Marcelino Calero y Portocarrero entre 1829 y 1831, constituye la primera publicación periódica especializada que trató los temas ferroviarios en lengua española. Trasladada a Sevilla durante 1832 y el primer cuatrimestre del año siguiente, terminó su período de publicación en Madrid. Su etapa londinense ofrece, no obstante, el interés léxico de mayor importancia, gracias al contacto de su autor con las explotaciones ferroviarias inglesas, de gran expansión en esos momentos.

La Guía del Comercio y Boletín de Fomento o el Boletín Oficial de Caminos, Canales y Puertos (1842-1844), el semanario de ciencias, artes, literatura e industria La Antorcha (1848-1849), el periódico semanal - posteriormente quincenal- Los ferro-carriles (1852-1853) o el dominical Gaceta de los caminos de hierro (1856) fueron algunas de las manifestaciones que adoptó la prensa especializada para tratar los temas ferroviarios en España 5 .

\section{e) Textos literarios}

Diversas obras literarias españolas publicadas entre 1840 y 1842 describieron a través de sus páginas la explotación ferroviaria que, en ese momento, se producía ya en algunos países europeos y en Cuba (Sagra, 1836).

El español Jacinto de Salas y Quiroga, que ya había experimentado en Inglaterra los caminos de hierro, publicó en 1840 sus Viages, en cuyo primer tomo dedicado a Cuba se describía el transporte mediante ferrocarril, instaurado en la isla tres años atrás. Entre 1840 y 1841, Ramón de Mesonero Romanos escribió sus Recuerdos de viaje por Francia y Bélgica. En el capítulo

5 La Antorcha fue publicada por D. Mariano Cubí Soler, a raíz de la inauguración de la primera línea peninsular entre Barcelona y Mataró, mientras que Los-ferrocarriles apareció de la mano de D. J. De Meniolagoitia, subdirector de la explotación de la línea Madrid-Aranjuez. 
diecisiete de esta obra se incluye una extensa descripción de los caminos de hierro belgas (Mesonero, 1881). Los Viages de Fray Gerundio por Francia, Bélgica, Holanda y orilla del Rhin, obra del escritor Modesto Lafuente, publicada en dos volúmenes en 1842, completa la terna de testimonios literarios de este breve - aunque fundamental - período de tiempo. En el primero de dichos volúmenes se relata, de forma autobiográfica, la primera experiencia ferroviaria en tierras francesas del personaje Fray Gerundio. En el segundo, fueron los caminos de hierro belgas los utilizados por Modesto Lafuente como entorno principal de su narración, aunque realizó también unos breves apuntes sobre los ferrocarriles alemanes, tras iniciar una de las etapas de su viaje en la estación ferroviaria de la ciudad de Colonia. En todo caso, sus comentarios, más allá de lo estrictamente ferroviario, se extendieron a aspectos socio-culturales de la época.

\section{f) Obras lexicográficas}

A la tradición académica y a la obra de E. de Terreros (1786-93) se unió por primera vez en el siglo XIX español una serie de obras lexicográficas de autor o de sociedades que, a imitación de las grandes empresas francesas, concibieron la lexicografía como negocio. Además, los textos lexicográficos especializados aumentaron en número y cubrieron diversos campos de la ciencia y de la técnica. Durante la segunda mitad de siglo, el léxico del ferrocarril fue una de las parcelas afortunadas en este sentido con la publicación, entre 1863 y 1887 , de tres diccionarios específicos sobre ferrocarriles.

El primero de ellos, el Vocabulario descriptivo de ferro-carriles, obra de Mariano Matallana del Rey, en 1863 director de caminos vecinales y canales de riego y jefe de sección de vías y obras en la compañía del ferrocarril de Zaragoza a Pamplona. Bajo el extenso título de Diccionario razonado legislativo y práctico de los ferro-carriles españoles bajo el aspecto legal, técnico, administrativo y comercial de los mismos aparece publicado en 1869 el segundo texto, obra de Benito Vicente Garcés, que contó con la colaboración de José González Álvarez. Finalmente, en 1887, se editó el Diccionario general de ferrocarriles legislativo, administrativo, técnico y comercial, elaborado por José González de las Cuevas y Francisco Sastre y Rodríguez, empleados en el Servicio de la Intervención y Estadística de la Compañía del Norte de España. El texto fue dirigido, a su vez, por Pedro Fernández del Rincón, abogado y secretario del consejo de administración de dicha compañía. 


\section{ESTUDIOS PROPIOS Y EN OTRAS LENGUAS}

Desde que el ferrocarril empezó a usarse como medio de transporte, la terminología con él relacionada ha sido estudiada. No obstante, en la lengua española sólo se han producido referencias y breves análisis relativos a términos concretos o a aspectos muy puntuales de este corpus léxico ${ }^{6}$. En fechas recientes, se han publicado algunos estudios de M. A. Martínez Lledó7.

En definitiva, los estudios de cierta profundidad han sido realizados fuera de nuestro país y describen el papel de dicha terminología en otras lenguas., Harvey J. Swann (1918) publicó a través de la Columbia University de Nueva York una obra compuesta por diversos estudios, en lengua inglesa, sobre la terminología francesa correspondiente a diferentes ámbitos de la ciencia y de la técnica. El primer capítulo, The terminology of the railroad, se dedicaba al análisis de la pugna existente entre el francés y el inglés por ocupar el campo léxico del ferrocarril durante el siglo XIX. Peter J. Wexler (1955) elabora una tesis de estado francesa sobre La formation du vocabulaire des chemins de fer en France (1778-1842). Publicada en Ginebra, constituye, sin duda, el mejor estudio léxico realizado sobre el ferrocarril. Para ello, abandona la postura puramente lingüística y entra de lleno en la historia social. Wexler presta atención a las fechas, a los lugares, a los acontecimientos y a la clasificación de los términos a partir de las realidades. Y Herbert Peter (1969) publicó en Sttutgart un trabajo que analiza la aparición y el desarrollo del léxico ferroviario italiano.

6 Se trata de anotaciones o informes relacionados con la terminología del ferrocarril que elaboraron en distintos momentos de la RAE algunos de sus miembros y que publicaron a través de su Boletín: A. Ma Segovia en 1859 o, entre 1914 y 1929, diversas aportaciones de D. de Cortázar, M. Velasco de Pando, P. de Novo y F. Chicarro. Posteriormente, PotTiER, B. (1966), TORRES MARTíneZ, J.C. (1969 y 1970).

7 En Borreguero ZuloAgA, M. et al. (2002) sobre la macroestructura de los diccionarios ferroviarios o la formación de lenguas especializadas a partir de la documentación del ferrocarril Córdoba-Málaga (1863-1873); en ECHENIQUE, E. et al. (2002) sobre la voz tranvía; o algunas referencias en la revista Vía Libre, publicada por la Fundación de los Ferrocarriles Españoles. Sin embargo, los datos aportados en este último caso muestran, por ejemplo, que la selección de las fuentes constituye un elemento fundamental para la correcta reconstrucción histórico-lingüística de disciplinas científicas y técnicas en cualquier lengua. El manejo parcial de los textos, desde un punto de vista cronológico, lleva a establecer algunas fechas erróneas para la fijación de los primeros usos de los términos ferroviarios. 


\section{4. ÁrbOL DE CAMPO}

El seguimiento del léxico del ferrocarril en todos los períodos se ha basado en una estructura de árbol de campo, que incluye los siguientes subcampos: Denominación del medio, Material fijo, Material móvil, Dependencias y construcciones, Personal, Circulación y servicios, Señalización y seguridad. A su vez, el Material fijo (superficies de deslizamiento y elementos adyacentes), el Material móvil (vehículos y mecanismos) y las Dependencias y construcciones (instalaciones e infraestructuras) se han subdividido en diversos subcampos, con el fin de acercar la realidad del ferrocarril a un tipo de estructura cognitiva. El diseño ha facilitado el plan de vaciado de las fuentes y el establecimiento de relaciones internas entre los términos.

\section{PERIODIZACIÓN}

El establecimiento de períodos cronológicos que permitan diferenciar las distintas fases del proceso no carece de ciertas dificultades. Es necesario evitar delimitaciones arbitrarias y la fijación de determinadas fechas debe conjugar textos y hechos. En materia ferroviaria, hasta la mitad del siglo XIX —en 1848 fue inaugurada la primera línea férrea peninsular-, las obras publicadas en lengua española que trataron, de algún modo, cuestiones ferroviarias rondaron la veintena. Durante la segunda mitad de siglo y, en especial, al amparo de la primera Ley General de Ferrocarriles de 1855 los textos se multiplicaron con la creación de diversas compañías, la realización de numerosos proyectos y la edición de un gran número de obras especializadas, entre ellas los tres diccionarios ferroviarios publicados en España en el siglo pasado. Se trata de centenares de obras que, con el cambio de siglo, pasaron a constituir miles de documentos.

La periodización se ha establecido en las siguientes fechas: Los primeros términos (1829-1835), un corte al que, tras un silencio en consonancia con la propia historia de España y el traslado de los proyectos ferroviarios a Cuba, siguen los Testimonios literarios (1840-1842), Un nuevo arranque (1844-1846), coincidente con los proyectos que dieron lugar a los primeros quilómetros españoles de vía férrea, Primeras incorporaciones lexicográficas (1846-1850), La consolidación del léxico ferroviario (1851-1862), La lexicografía ferroviaria (1863-1887) y, finalmente, El cambio de siglo (1888-1910). 


\section{LOS PRIMEROS TÉRMINOS.}

Cabe decir que en el primer período, fijado entre 1829 y 1835, el proceso de introducción del léxico del ferrocarril estuvo relacionado con varios hechos fundamentales. Entre ellos destacan los siguientes:

- los intentos más tempranos para establecer lo ferrocarriles y su correspondiente terminología se produjeron varias décadas después que en Inglaterra y Francia;

- en sus inicios, el léxico ferroviario tuvo poca difusión, únicamente a través de escasos textos especializados;

- los tecnicismos se introdujeron, en gran medida, a partir de las traducciones francesas de los manuales ingleses originales, de transcripciones (que dieron lugar a voces como locomotivo, túnel o vagón) y de calcos, va través de términos como silla o durmiente, procesos todos ellos realizados a partir del inglés;

- varios términos del ferrocarril se tomaron prestados del vocabulario tradicional del transporte terrestre o marítimo; el léxico del transporte terrestre ordinario aportó al vocabulario del ferrocarril términos pertenecientes a los ámbitos de trazado (andén, camino, carril, crucero, tránsito) y de los vehículos y mecanismos (carro, carruaje, coche, ómnibus, reata, tren o tirante); la terminología marítima aportó, en especial, voces relacionadas con las operaciones y maniobras de la circulación (alijar, amarrar, embarcar, lastrar, remolcar, transbordo, muelle o cabestrante);

- el recurso de la metáfora sirvió para configurar un grupo de tecnicismos nada despreciable, bien de tipo antropomórfico (costilla, muñonera), animal (caballo de hierro) o por semejanza en la forma o función (arista, filete, mortaja).

\section{TESTIMONIOS LITERARIOS}

Entre 1840 y 1842 , las obras literarias se convirtieron en fuente de documentación de la terminología del ferrocarril. Una de las intenciones de los libros de viaje de la época consistió en reflejar las realidades más novedosas que sus autores observaban. En los aspectos ferroviarios más dinámicos se centró, por ello, su interés. El movimiento de los vehículos y el trasiego y la vitalidad de los lugares y construcciones relacionadas con el ferrocarril colmaron dicho interés y aportaron la plasticidad y el colorido que este género 
literario estaba en condiciones de aprovechar. Los fenómenos léxicos observados en estos textos se centran en dos aspectos fundamentales:

- por una parte, se emplearon voces y expresiones ya utilizadas con anterioridad, si bien algunos de estos términos sufrieron cambios o ampliaciones significativas, en especial por influencia de la lengua francesa;

- por otra parte, apareció un nuevo grupo de términos tomados del francés que, por lo general, también aludieron a nuevos referentes del ámbito de las dependencias y los vehículos ferroviarios.

Ambas orientaciones se reflejan en aspectos como la representación del modelo francés de taxonomía de los vehículos ferroviarios a través de términos como berlina, charabán, diligencia y furgón, o el uso consolidado de voces como locomotor, convoy, tren, etc. De igual forma, la lengua francesa amplió los horizontes semánticos de determinadas voces o prestó algunas nuevas en relación a los puntos de encuentro de la circulación por ferrocarril, representados por términos como bagaje, departamento, establecimiento, estación o gabinete, a ciertas infraestructuras mediante voces como bóveda o galería, y a vehículos muy concretos como el ténder.

\section{NUEVO ARRANQUE Y DESARROLLO.}

A partir de 1844, y hasta 1862, tuvo lugar una primera fase en el proceso de desarrollo y consolidación de la terminología ferroviaria española en su estado más semejante al actual. Entre los fenómenos léxicos más relevantes de esta etapa destacan los siguientes:

- el progresivo aumento de la voz ferrocarril, que empezó a ocupar el espacio semántico de la lexía camino de hierro;

- las primeras incorporaciones lexicográficas relativas al campo ferroviario en los diccionarios de autor;

- la creciente consolidación de anglicismos como balasto, coque, locomotiva, raíl, truck, túnel o vagón, que complementó la importante influencia inicial de la lengua francesa.

Sobre esta última característica, cabe recordar que durante este período fue muy numerosa la participación de técnicos y empresas inglesas en los primeros proyectos ferroviarios españoles. 


\section{CONSOLIDACIÓN Y LA LEXICOGRAFÍA FERROVIARIA.}

1863 y 1887 delimitan la segunda fase del proceso de implantación definitiva de la terminología ferroviaria española, Por una parte, la explotación del nuevo medio de transporte hizo que el campo léxico relacionado con la circulación y los servicios administrativos ferroviarios aumentara el volumen de voces y expresiones utilizadas. Por otra, la publicación de tres diccionarios especializados en este cuarto de siglo y la incorporación de numerosas voces del campo del ferrocarril en el Diccionario Académico caracterizaron dicho período. En conjunto, las características lexicográficas más relevantes de todo el proceso fueron las siguientes:

- entre los subcampos que forman el árbol de campo utilizado para el análisis de la terminología ferroviaria hay diferencias en cuanto al grupo de diccionarios donde se produjo la primera incorporación lexicográfica de los términos, de modo que los diccionarios de autor publicados entre 1846 y 1863 se anticiparon al $D R A E$ al fijar varios términos de los subcampos referidos al Material móvil y a las Dependencias y construcciones, al mismo tiempo que se caracterizaron por incluir las voces que han penetrado con mayor facilidad en el vocabulario general y, a su vez, por haber recibido un gran número de términos del lenguaje común;

- a partir de 1863, y hasta 1887 , los diccionarios especializados sobre ferrocarriles se anticiparon, como era de esperar, a los diccionarios de autor y a las ediciones del DRAE de ese período en la incorporación de voces ferroviarias, e incluyeron un número considerable de galicismos como tirafondo, eclisa, etiqueta, gabarit, factaje, tasa, etc., con un seguimiento más que probable de la lexicografía francesa;

- con frecuencia, los diccionarios no académicos incluyeron comentarios metalingüísticos y de uso al definir determinadas voces ferroviarias, lo cual pone de manifiesto los problemas e indecisiones inherentes a la incorporación a una lengua de un léxico especializado.

\section{EL CAMBIO DE SIGLO.}

Los miles de documentos ferroviarios en lengua española que ha generado el siglo XX ofrecen ya un abanico de posibilidades ilimitado para el análisis histórico, pero además constituyen el solar sobre el que debe descansar toda normalización terminológica. Algunos datos curiosos, con una mirada al pa- 
sado, pueden llevar a una reflexión de futuro. Valga, de este modo, el siguiente itinerario (Rodríguez Ortiz, 1998b, 217-227): años 1852-1854, revista Los Ferro-carriles, alusión al «tachómetro, que marca a los maquinistas el grado de velocidad que el tren lleva»; en 1933, espidómetro, término recogido por A. Fernández García en su obra dedicada a los anglicismos del español entre 1891-1936; desde el DRAE de 1936, voz cursómetro, definida como «aparato que se aplica a medir la velocidad de los trenes del ferrocarril»; y hoy día, además, velocímetro, que a partir del apéndice a la edición del DRAE de 1970 es el «aparato que en un vehículo indica su velocidad de traslación», mientras que el tacómetro, cuyo primer étimo griego expresa rapidez, es el «aparato que mide el número de revoluciones de un eje».

\section{PROPUESTAS PARA OTROS CAMPOS}

En primer lugar, el léxico del ferrocarril no difiere de otros grupos de tecnicismos de la lengua española del siglo XIX. Las relaciones entre lengua, cultura y sociedad y la propia historia del desarrollo científico-técnico español, principalmente en su contacto con el resto de países y de lenguas influyentes, hacen que entre los lenguajes de especialidad surgidos en el siglo pasado existan puntos comunes en relación con los préstamos léxicos o los calcos semánticos.

Traducciones de manuales técnicos, semanarios especializados, diccionarios, documentos administrativos o textos literarios no deben quedar al margen de la deseada fidelidad descriptiva y, por tanto, más allá del mero dato cronológico, nos deben acercar a esa correspondencia exigible entre lenguaje y realidad, relacionando los hechos de lengua y el desarrollo histórico de las distintas disciplinas científico-técnicas

Hay que considerar, en todo caso, las situaciones de trasvase léxico entre los lenguajes de especialidad y el lenguaje común, así como el contexto social en que se producen. El léxico del ferrocarril, que en mayor o menor grado podemos concebir como especializado de carácter técnico, ha permitido, mediante una serie de voces arraigadas en la lengua común, la formación incluso de frases hechas de tipo coloquial como farolillo rojo, ser el furgón de cola, para parar un tren, a todo tren, perder el último tren, de vía estrecha $\mathrm{o}$, incluso, válvula de escape, así como la existencia de diversos casos de polisemia desde denominaciones populares como cangrejo, que presenta cuatro referentes distintos: 'placa giratoria', 'plataforma o truck', 'vagoneta' o 'tranvía de color encarnado'. 
En resumen, otros campos de especialidad como el mundo del automóvil, la aviación o el motociclismo, sin alejarnos de los medios de transporte, pueden ser objeto de estudio desde este planteamiento conjunto entre la historia de la lengua y la historia de las ciencias y las técnicas decimonónicas.

\section{BIBLIOGRAFÍA}

BARRA, F.J. (1833), Comparación entre los caminos ordinarios, los caminos de hierro y los canales de navegación, Madrid, Imprenta de D. Miguel de Burgos.

Borreguero Zuloaga, M. et al. (2002), Anuario de la Asociación de Jóvenes Investigadores de Historiografía e $H^{a}$ de la Lengua, 1, Madrid, AJIHLE.

CAlero y Portocarrero, M. (1929-1931), Semanario de Agricultura y Artes, Londres.

CORTÁZAR, D. de (1914), «El purismo», en BRAE, I, pp. 39-42, 147-150.

CORTÁZAR, D. de (1915), «El purismo», en BRAE, II, p. 353.

Cubí Soler, M. (1848-1849), La Antorcha, Barcelona, Imprenta de Antonio Teixidó y Francisco Granell.

DUVERNE, T. (1826), Traité pratique sur les chemins en fer et sur les voitures destinées a les parcourir, París, Bachelier.

ECHENIQUe, E. et al. (2002), Actas del V Congreso Internacional de $H^{a}$ de la Lengua Española, Madrid, Gredos, vol. II, pp. 2211-2224.

EscosurA, G. de la (1831), Tratado de las máquinas de vapor, Madrid, Imprenta de D. León Amarita.

GonzÁlez Azaola, G. (1831), Tratado práctico sobre los carriles de hierro, y los carruajes, máquinas de vapor y de gas, ya movibles ó loco-motrices, ya estables y cuanto conviene saber para construirlos, Madrid, Oficina de D. Federico Moreno.

GonzÁlez De Las Cuevas, J.; SASTRe y RodríGuez, F. (1887), Diccionario general de ferrocarriles legislativo, administrativo, técnico y comercial, Madrid, Establecimiento tipográfico de Manuel Minuesa.

Gutiérrez CuAdrado, J.; PESET, J.L. (1997), Metro y Kilo: El sistema métrico decimal en España, Historia de la Ciencia y de la Técnica, 35, Madrid, Akal.

LAFuente, M. (1842) Los Viages de Fray Gerundio por Francia, Bélgica, Holanda y orilla del Rhin.

MATAllana DEL REY, M. (1863), Vocabulario descriptivo de ferrocarriles con la legislación de los mismos, Zaragoza, Imprenta y librería de Roque Gallifa.

Mellet, F.N. (1828), Traité des machines à vapeur, París, Bachelier. 
Meniolagoitia, J. de (1852-1854), Los ferro-carriles, Madrid, Imprenta de L. García y José C. de la Peña.

Mesonero Romanos, R. de (1881), Recuerdos de viaje por Francia y Bélgica en 1840 á 1841, Madrid, Oficina de la Ilustración Española y Americana.

Novo, P. de; ChICARro, F. (1929), «Acerca del indebido empleo de la palabra cabina», en $B R A E$, XVI, pp. 78-79.

PETER, H. (1969), Entstehung und ausbildung der italienischen eisenbahnterminologie, Sttutgart, Wilhelm Braumüller.

Pottier, B. (1966), «Le développement du vocabulaire des chemins de fer», Mélanges a la mémoire de Jean Sarrailh, 261-264.

Rodríguez ORTIZ, F. (1996), «El léxico de los caminos de hierro en el español», Actas del III Congreso Internacional de Historia de la Lengua Española, Madrid, Arco Libro, vol. II, pp.1511-1519.

RODRÍGUEZ ORTIZ, F. (1997), Introducción y desarrollo del léxico del ferrocarril en la lengua española (Tesis doctorals microfitxades, 3093), Barcelona, Publicacions Universitat de Barcelona.

RODRÍGUEZ ORTIZ, F. (1998a), «Tratados ferroviarios en España: primeras traducciones», Estudios de Historia de las Técnicas, Arqueología Industrial y Ciencias, Junta de Castilla y León, Consejería de Educación y Cultura, vol. I, pp. 449-455.

RODRÍGUEZ ORTIZ, F. (1998b), «Diacronía de la formación de derivados y compuestos en el léxico ferroviario español», Actes del Col.loqui La Història dels Llenguatges Iberoromànics d'Especialitat (segles XVII-XIX). Solucions per al present, Barcelona, IULA, Universitat Pompeu Fabra, pp. 217-227.

RODRÍGUEZ ORTIZ, F. (2001), «Americanismos ferroviarios: una apuesta léxica», Estudios sobre el español de América, Burgos, Universidad, pp.1240-1247.

SAgRA, R. de la (1836), Cinco meses en los Estados Unidos de la América del Norte. Libro de viajes, París, Librería de Renouard.

SALAS Y QUIROGA, J. de (1840), Viages.

SEgOVIA, A.M (1859), «Neologismo y arcaísmo», en BRAE, I, 1914, pp. 291-297.

SWANN, H.J. (1918), «The terminology of the railroad», en French terminologies in the making. Studies in conscious contributions to the vocabulary, Nueva York, pp.1-34,

TERreros y PANDo, E. de (1786-1793), Diccionario Castellano con las voces de ciencias y artes, Madrid, Imprenta Viuda de Ibarra.

TORRES MARTíNEZ, J.C. (1969), «Notas sobre el léxico ferroviario», BFE, XXX, pp. 9-25.

TORRES MARTÍNEZ, J.C. (1970), «Reseña al Lexique general des termes ferroviaires de la Union Internationale des Chemins de Fer», BFE, XXXVI-XXXVII, pp. 81-83.

Velasco DE PANDo, M. (1923), «Varias cédulas sobre voces técnicas», en BRAE, X, pp. 253-260. 
Velasco De Pando, M. (1924), «Varias cédulas sobre voces técnicas», en $B R A E$, XI, pp. 225-228.

VÍA LIBRE, en www.vialibre-fe.com/diccionario/consultas.htm

ViCENTE GARCÉS, B. (1869), Diccionario razonado legislativo y práctico de los ferrocarriles españoles bajo el aspecto legal, técnico, administrativo y comercial de los mismos, Madrid, Imprenta del indicador de los caminos de hierro.

WEXLER, P.J. (1955), La formation du vocabulaire des chemins de fer en France (17781842), Ginebra, Société de Publications Romanes et Françaises. 